\title{
Effect of Benson Relaxation on Fatigue of Nurses Working in Intensive Care Units
}

Tahereh Najafi Ghezeljeh ${ }^{1}$, Hojatollah Sedghian $^{1 *}$, Fatemeh Mohaddes Ardabili², Habibollah Rezaei Loieh ${ }^{3}$

1. Department of Intensive Care Unit, School of Nursing and Midwifery, Iran University of Medical Sciences, Tehran, Iran. 2. Department of Medical Surgical Nursing, School of Nursing and Midwifery, Iran University of Medical Sciences, Tehran, Iran

3. Shahid Rajaei Cardiovascular, Medical and Research Center, Tehran, Iran.

cittation: Najafali Ghezeljeh, T, Sedghian, H, Mohaddes Ardabili, F \& Rezaei Loieh, H 2016, 'The effect of teaching critical thinking skills on the decision making style of nursing managers', Journal of Client-Centered Nursing Care, vol. 1, no. 4, pp. 211-217.

Article info:

Received: 21 Jun. 2015

Accepted: 08 Oct. 2015
Keywords:

Relaxation, Nurse, Fatigue

\begin{abstract}
A B S T RA C T
Background: Fatigue is one of the important factors in nursing performance because it affects the quality of care provided to the patients. In this regard, some complementary interventions such as Benson relaxation techniques may relieve fatigue. This study aimed to evaluate the effect of Benson relaxation on fatigue of nurses working in intensive care units.

Methods: This is an experimental study (pretest-posttest randomized with control group) conducted on 63 nurses working in intensive care units of Shahid Rajai Cardiovascular, Medical and Research Center in Tehran, Iran. Participants were selected by stratified sampling based on wards and were randomly allocated in the intervention and control groups. Benson relaxation method was performed by nurses in the intervention group for 20 minutes twice a day with at least 6 hours interval between 2 sessions. The relaxation therapy was scheduled for 2 weeks. The data were collected via demographic and fatigue questionnaires. After data collection, the Chi-square test, independent t-test, Fisher exact test, and analysis of variance with repeated measures were performed by SPSS, version 21 .

Results: The results showed that the mean(SD) of fatigue score in the intervention group before, 1, and 2 weeks after intervention were 4.73(0.97), 4.58(0.94), and 4.38(0.85), respectively. Two groups had significant differences in terms of fatigue as the mean fatigue score of the control group increased over time compared to that of the intervention group $(\mathrm{P}=0.002)$. Also, there was a significant difference (it decreased) between the mean fatigue score of the nurses before the intervention and 2 weeks after the intervention. However, the mean of fatigue in the control group increased over time.
\end{abstract}

Conclusion: Implementation of Benson relaxation was associated with decreased fatigue of nurses in intensive care units. Therefore, we suggest that managers and authorities of health centers consider Benson relaxation method a part of fatigue reduction plans for nurses.

\footnotetext{
* Corresponding Author: 


\section{$\mathrm{T}$}

\section{Background}

oday, human resources, the most valuable capital in the organizations, encounter with many problems at work places. Organizational psychologists and management experts mostly focus on factors effective on increasing or decreasing human efficiency. They attempt to identify these factors, and use strategies to strengthen positive factors and weaken negative factors. Nurses with their crucial role in health service system can play important role on improving health care issues (Samadpour 2009). Thus, dealing with the problems affecting performance and productivity of nurses is of great importance (Salamzadeh, Mansori \& Farid 2008).

Due to special nature of nursing profession in dealing with patients' pain, complications, and death on one hand and its rotational work shifts on the other hand, mental and physical health of nurses are at risk. All these factors can create physical and emotional problems such as depression, hopelessness, chronic fatigue, and low energy (Morse et al. 2012). Results of Senjeri et al. (2009) study showed that fatigue was one of the most common problems reported by nurses. Fatigue was associated with job injuries and highest fatigue was reported due to rotational shifts and these people had the highest reported chronic fatigue. Fatigue can lead to unsuitable behavior, provocation, avoiding work, pain, and lack of concentration (Adriaenssens et al. 2012), also indifference to patient, low self-confidence, job dissatisfaction, and intention to leave (Kuerer et al. 2007). The nurses with physical, mental, and emotional fatigue cannot take care of the patients properly. They feel incompetent in handling the patients and this leads to low self-confidence and failure (Yaghobinia et al. 2005).

Intensive care units (ICUs) create much tension compared to other wards. These tensions can affect the staffs' mental health and performance in these wards (Norian, Parvin \& Mehrabi 2010). According to Gholipour Baradari et al. (2012), fatigue like tension and anxiety was effective on the patient's safety. This shows the significance of dealing with this issue and taking suitable measures to reduce it (Raftopoulos, Charalambous \& Talias 2012).

The significance of nurse fatigue lies in its harmful consequences. For example, many studies have shown that a strong association exists between nurse fatigue and making mistakes (Saremi \& Falah 2013). Evaluation of tension, anxiety, and fatigue among nurses has shown that some of their causes can be controlled by health authorities and managers. However, some factors cannot be changed due to their nature (i.e. working with patients). Thus, fatigue can be reduced by emotional-oriented adjustment techniques as relaxation tech- nique, music therapy, respiratory exercises, etc. And, some adjustments can be done in a person to relieve these tensions (Shahsavari et al. 2008; Hosseini et al. 2011; Memarian 2011).

Various techniques have been mentioned in different studies to prevent fatigue. Concentration method is an effective method to reduce fatigue and tension (Smeltzer et al. 2010). Another method is Benson relaxation. Introduced by Herbert Benson (1970), it is an easy method to teach to others (Monahan et al. 2007). In his study regarding various tension elimination techniques, 4 components are basic to all techniques of concentrative meditation: A quiet environment, a mental device, a passive attitude, and a comfortable position (Benson, Kotch \& Crass 1997). Benson relaxation with its great advantages and easy implementation has no adverse effects and people can use it independently. The results of Shahriari et al. (2012) study showed that relaxation was effective on reducing depression, anxiety, and tension of mothers with mentally-retarded daughters. This method was already used in the reduction of fatigue of patients with chronic illnesses (Basiri Moghadam et al. 2013; Kushan et al. 2013). Regarding the Benson relaxation benefits and the significance of nurses' fatigue reduction, this study aimed to determine the effect of Benson relaxation on the fatigue of nurses working in ICUs.

\section{Materials \& Methods}

This is an experimental study (pretest-posttest randomized control group). Stratified samples were selected based on wards and study samples were randomly allocated to the intervention and control groups. The inclusion criteria were as follows: being unfamiliar with the methods of muscular relaxation, having no thyroid dysfunction or mental disease, including anxiety, not taking any anxiety drugs, having a full time job in ICU with at least 6 months of experience. Exclusion criteria were as follows: Experiencing a tension event (e.g. losing one of the relatives) during the study based on one's report, being absent in educational sessions and not using correct method of Benson relaxation at house (i.e. less than 10 sessions per week) (registration in self-reporting checklists). To determine sample size, confidence interval was set at $\% 95$ and the intervention power $84 \%$. Because the effect of Benson relaxation on anxiety and fatigue of ICU nurses with control group has a difference of at least $7(\mathrm{~d}=7)$, it is statistically significant. The number of samples is calculated by the following formula.

$$
\frac{n=\left[\left(Z_{1-\alpha / 2}+Z_{1-\beta}\right)^{2} \times 2 s^{2}\right]}{d^{2}}
$$


Also, based on the study of Hassan Pordehkordi et al. (2009) and assuming 10\% sample loss in each group, 35 people should be selected for each group. Thus, the total sample size was determined as 70 . In the study period, 7 nurses were excluded from study due to lack of doing relaxation based on practical definition or their incomplete questionnaires. At the end of study, 31 nurses were in intervention group and 32 in the control group.

The study instruments included demographic questionnaire and of fatigue visual evaluation questionnaire. The demographic questionnaire comprised questions about age, gender, marital status, number of children, education, work shift, work experience, working in other therapy centers, income adequacy, working hours per week, sport, and background disease. For data collection of fatigue severity, fatigue severity scale (FSS) was applied. This scale evaluates subject's fatigue in the past 7 days and consisted of 9 items. Each item was scored from 1 to 7 and Nurses mark them to show their fatigue. Mean score of 9 items was considered as fatigue level and the highest mean showed higher fatigue level. The minimum score was 1 and maximum 7 . The mean score of equal or higher than 5 was classified as severe fatigue (Valko et al. 2008; Johansson et al. 2014). The validity and reliability of this scale were verified by Valko et al. (2008) and Troy and Daglas (2003).

In the study by Salehpour et al. entitled "Psychometric features of fatigue severity scale in the patients with sclerosis", it was shown that Persian version of FSS had satisfactory psychometric features and can be applied in clinical and study situations (Salehpour et al. 2012). To evaluate content validity, the questionnaire was given to 10 lecturers of Nursing and Midwifery School of Iran University of Medical Sciences. Based on their opinion, necessary changes were made in the questionnaire. To determine reliability, the questionnaire was given to 10 nurses in the ICU. The data were investigated and internal consistency of instrument was computed and its Cronbach $\alpha$ was 0.96 . According, the data of 10 participants in the main part of study were not considered.

This study was supported by the Ethics Committee (IUMS.REC.1394.9211449209) of Deputy of Research and Technology of Iran University of Medical Sciences. After taking permission for the study, the researcher referred to ICU of Shahid Rajai Cardiovascular, Medical and Research Center and explained the purpose of the study to the nurses and took their consent. Then, the study subjects were selected and randomly allocated in the control and intervention groups.
Before intervention, demographic form and FSS were given to nurses of both groups at the early morning shift. In intervention group, after the end of work shift, Benson relaxation method was completely explained in a theoretical session to the nurses, also Benson relaxation stages were provided in a pamphlet and were given to nurses. Then, 2 days later in a practical session, the recorded instruction of Benson relaxation was given via headphone to the nurses and they were asked to perform it according to the instructions. Furthermore, their questions regarding Benson relaxation method were answered.

The Benson relaxation can eliminate errant stress responses. It starts with saying a relaxing word (e.g. God) and continues with deep and regular breathing. The subjects would deeply inhale through the nose, exhale through the mouth, and repeat the desired word in their minds. Simultaneously, they relax their muscles from the fingertips upward until the complete relaxation of all the muscles in the body. This state was maintained for 20 minutes. Then, the subjects open their eyes. The stages were followed carefully during this activity by an audio file. This instruction audio file took 20 minutes and there was no need to set the time by the clock.

After educational sessions and assurance of subjects' learning, they perform relaxation exercises 2 times a day (morning and afternoon and each session for 20 minutes with an interval of at least 6 hours) for 2 weeks. The daily form was given to the intervention group to register their following course of Benson relaxation at home and in case of missing the relaxation at home was investigated by this form. The researcher also called participants 2 times a week to promote, support, and evaluate study units regarding their progression in relaxation method. The control group did not receive Benson relaxation method.

One or 2 weeks after starting Benson relaxation method, FSS questionnaire was given to nurses of 2 groups in the early morning shift. All data were analyzed using Statistical Package for the Social Sciences (version 21, SPSS Inc, Chicago, IL). In this regard, independent $t$ test was used to compare mean fatigue score between intervention and control groups in each time period (before intervention, 1 week after intervention, and 2 weeks after intervention) and also to evaluate their age and work experience.

The Fisher exact test was used to compare 2 groups in terms of gender, marital status, and education, and the Chi-square test was used to compare work shift and income adequacy. Finally, Repeated Measure Analysis Variance test was used to compare participants' fatigue 
scores in the study period. A significance level of 0.05 was set for tests of hypothesis.

\section{Results}

Based on the demographic findings, ages of most participants ranged between 26 and 35 years. Most of them (84\%) were women, $63 \%$ married and most of them $(92 \%)$ had Bachelor of Science in Nursing, and $63 \%$ had rotational shift. Also, most of them $(50 \%)$ had a work experience of 5 years or less. In terms of income adequacy, they stated that their income was somewhat adequate. Both groups were statistically similar in all mentioned items except age and work experience (Table 1). However, the results showed that these 2 variables had no significant association with fatigue variable. Thus, age and work experience were not confounding variables.

The findings showed that mean score of fatigue in the control group before intervention was $4.72(0.82)$. It was $4.79(0.86)$ at the end of the first week after intervention and increased to 5.02(0.75) at the end of the second week after the start of intervention. The mean score of fatigue in intervention group before the intervention was 4.73(0.97). It changed to $4.58(0.94)$ at the end of the first week after intervention and decreased to $4.38(0.85)$ at the end of the second week after intervention.

Table 1. Demographic characteristics of the intervention and control groups $(n=63)$.

\begin{tabular}{|c|c|c|c|c|c|c|}
\hline \multirow{2}{*}{ Variables } & \multirow{2}{*}{ Groups } & \multicolumn{2}{|c|}{ Control } & \multicolumn{2}{|c|}{ Benson relaxation } & \multirow{2}{*}{ P-value } \\
\hline & & Mean(SD) & No. (\%) & Mean(SD) & No. (\%) & \\
\hline Age, y & & $36.75(7.10)$ & & $32.97(5.27)$ & & 0.020 \\
\hline Gender & $\begin{array}{l}\text { Female } \\
\text { Male }\end{array}$ & & $\begin{array}{c}28(87.5) \\
4(12.5)\end{array}$ & & $\begin{array}{l}25(80.6) \\
6(19.4)\end{array}$ & 0.509 \\
\hline Marital status & $\begin{array}{l}\text { Married } \\
\text { Single } \\
\text { Divorced }\end{array}$ & & $\begin{array}{c}21(65.6) \\
10(31.3) \\
1(3.1)\end{array}$ & & $\begin{array}{c}12(38.7) \\
19(61.3) \\
0\end{array}$ & 0.408 \\
\hline Education & $\begin{array}{l}\text { BA } \\
\text { MA }\end{array}$ & & $\begin{array}{c}30(93.8) \\
2(6.3)\end{array}$ & & $\begin{array}{c}28(90.3) \\
3(9.7)\end{array}$ & 0.672 \\
\hline $\begin{array}{l}\text { Work experi- } \\
\text { ence }\end{array}$ & $\begin{array}{c}5 \text { years and less } \\
10-6 \\
15-11 \\
\text { Above } 16\end{array}$ & & $\begin{array}{l}13(40.6) \\
7(21.9) \\
6(18.8) \\
6(18.8)\end{array}$ & & $\begin{array}{c}19(61.3) \\
8(25.8) \\
4(12.9) \\
0\end{array}$ & 0.007 \\
\hline Work shift & $\begin{array}{c}\text { Fixed } \\
\text { Rotational }\end{array}$ & & $\begin{array}{l}13(40.6) \\
19(59.4)\end{array}$ & & $\begin{array}{l}10(32.3) \\
21(67.7)\end{array}$ & 0.490 \\
\hline $\begin{array}{l}\text { Income } \\
\text { adequacy }\end{array}$ & $\begin{array}{c}\text { Adequate } \\
\text { To some extent } \\
\text { Adequate } \\
\text { Inadequate }\end{array}$ & & $\begin{array}{c}7(21.9) \\
10(40.6) \\
12(37.5)\end{array}$ & & $\begin{array}{l}5(16.1) \\
14(45.2) \\
12(38.7)\end{array}$ & 0.838 \\
\hline
\end{tabular}

Table 2. Comparing the mean fatigue scores of contorl and intervention groups before, 1 , and 2 weeks after Intervention ( $\mathrm{n}=63)$.

\begin{tabular}{|c|c|c|c|}
\hline Stage Gorup & $\begin{array}{l}\text { Contorl } \\
\text { Mean(SD) }\end{array}$ & $\begin{array}{l}\text { Intervention } \\
\text { Mean(SD) }\end{array}$ & $\begin{array}{l}\text { The results of independent t-test } \\
\text { and P-value }\end{array}$ \\
\hline Before intervention & $4.72(0.82)$ & $4.73(0.97)$ & $\begin{array}{c}t=-0.056 \\
d f=61 \\
P=0.95\end{array}$ \\
\hline One week after intervention & $0.86(4.79)$ & $4.58(0.94)$ & $\begin{array}{c}t=0.96 \\
d f=61 \\
P=0.33\end{array}$ \\
\hline Two weeks after intervention & $5.02(0.75)$ & $4.38(0.85)$ & $\begin{array}{c}t=3.206 \\
d f=61 \\
P=0.002\end{array}$ \\
\hline $\begin{array}{l}\text { Repeated measure analysis vari- } \\
\text { ance test }\end{array}$ & $\begin{array}{c}\mathrm{F}=11.233 \\
\mathrm{df}=61 \\
\text { P-value }<0.001\end{array}$ & $\begin{array}{c}F=6.387 \\
d f=61 \\
\text { P-value }=0.003\end{array}$ & \\
\hline
\end{tabular}


There was no significant difference between intervention and control groups with regard to mean fatigue scores before the intervention $(\mathrm{P}=0.95)$. This difference was not significant after the first week $(\mathrm{P}=0.33)$ too. However, it got significant at the end of the second week $(\mathrm{P}=0.002)$. In other words, the mean score of fatigue among nurses in intervention group at the end of second week was lower than that of nurses in the control group (Table 2).

\section{Discussion}

The present study aimed to determine the effect of Benson relaxation method on anxiety and fatigue of nurses working in ICUs. By improving automatic nervous system and relaxing muscles, Benson relaxation promotes the individual and social performance and also improves positive feeling in a person (Komjathy 2015). The findings of the present study showed that intervention and control groups were similar in terms of fatigue scores before intervention. In other words, the mean scores of fatigue in both groups was about 4.7. With regard to fatigue scale, the score 5 or more than 5 was considered severe fatigue, so mean score of 4.7 showed high fatigue among nurses of both groups before intervention. In the study by Behboudi et al. (2014) evaluating the effect of aerobic sport of stretching on fatigue severity of nurses in Neonatal ICUs, fatigue severity mean before sport activities was 6.45 (severe). In the study by Meadors and Lamson (2008), 38\% of nurses were exposed to average fatigue and $39 \%$ to severe fatigue. In the study by Delpasand et al. (2011) evaluating the relationship between emotional intelligence and job burnout of ICU nurses, job burnout was high in terms of emotional fatigue.

The results of the mentioned studies were consistent with the result of the present study. In the intervention group, nurses had low fatigue in the first and second weeks. In addition, fatigue decreasing trend was found after Benson relaxation for 2 weeks compared to the previous state and one week after intervention. At the end of the first week and after Benson relaxation method, the mean fatigue scores of nurses decreased compared to the state before intervention. Again at the end of the second week, after Benson relaxation method, the mean fatigue score of nurses was lower compared to the end of the first week. The findings of the present study showed that compared to control group, Benson relaxation method had positive effect on fatigue of ICU nurses and reduce their fatigue. However, a review of literature shows the lack of study regarding the effect of Benson relaxation on fatigue of nurses, and some researchers dealt with the effect of other relaxation techniques on fatigue.
In the research of Behboudi et al. (2014), the study participants performed stretching exercises at the end of work shift for 10-15 minutes for 8 weeks. The fatigue score of nurses at the end of fourth week reduced compared to before intervention. Also, fatigue score at the end of the eighth week reduced compared to the end of the fourth week. In the study of Chen, Fang and Fang (2015), the effect of aromatherapy on improving job tension signs in nurses was evaluated. In this study, nurses of intervention and control (placebo) groups had small bottles hanging in the shift for 4 days. All job burnout signs, including fatigue of nurses reduced after aromatherapy.

Although no study has been performed with regard to the effect of Benson relaxation on fatigue of nurses or healthy people, some studies were conducted on the effect of relaxation methods on fatigue of patients. Basiri Moghadam et al. (2013) evaluated the effect of muscular progressive relaxation method on the fatigue of patients undergoing hemodialysis. In this study, muscular progressive relaxation method reduced fatigue level of the patients.

In the study done by Kushan et al. (2013), the effect of Benson relaxation method was evaluated on the fatigue of patients undergoing hemodialysis. It was found that Benson relaxation method reduced fatigue of patients in the intervention group.

Based on the results of the present study, Benson relaxation method as an intervention or a technique of complementary medicine in ICU nurses can significantly reduce fatigue. The results showed that long-term practice of Benson relaxation method reduced fatigue level of intervention group and had better effect on fatigue reduction. The nurses can be trained on doing Benson relaxation at home or at the end of work shifts. Managers and authorities of health centers are recommended to provide facilities in their centers with the aim of training these methods and create the conditions after work shift for healthcare workers namely ICU nurses.

According to the results, ICU nurses had high anxiety and fatigue. Thus, educational workshops of these nonmedication methods were of great importance to train the nurses in ICU wards. As one of the study inclusion criteria was working as a nurse in ICU, we suggest to perform a similar study to evaluate the effect of Benson relaxation on the fatigue of nurses of other wards. Because many factors are effective on fatigue of ICU nurses, we suggest to determine other strategies to alleviate the fatigue. We also suggest that in further studies, the effect of this method be evaluated in the long-term. 
One of the limitations of study was probable miss of doing relaxation method at home by nurses or their false report. In this regard, we tried to motivate their interest and take the participants' consent. As the exclusion criterion was performing the method less than 10 times in a week, the nurses' consent was taken before performing the method. Other limitations of study were contamination of control group's information. Because the learning of method was time consuming and practical exercise was required, pollution probability was low. Also, random group was preferred to control the group with regard to avoiding of data transmission. Because of selfreport in data collection method and intervention nature, study blinding was not possible.

\section{Conflict of Interest}

The authors declared no conflict of interests.

\section{Acknowledgements}

Researchers are grateful to authorities and nurses of ICU of Shahid Rajayi Hospital of Tehran. This paper is based on additional findings of research design approved by Iran University of Medical Sciences with the code IR.IUMS.REC.1394.9211449209. Our gratitude goes to Research Deputy of Iran University of Medical Sciences for supporting this study.

\section{References}

Adriaenssens, J, de Gucht, V \& Maes, S 2012, 'The impact of traumatic events on emergency room nurses: Findingsfrom a questionnaire survey', International Journal of Nursing Studies, vol .49 , no. 11 , pp. $1-12$.

Basiri Moghadam, M, Madadkar Dehkordi, SH, Mohammadpour, A \& Vaezi, AA 2013, '[Effect of Progressive Muscle Relaxation Technique on Fatigue in Patients Undergoing Hemodialysis (Persian)]', Journal of Preventive Care in Nursing $\mathcal{E}$ Midwifery, vol. 3, no. 2, pp. 24-32

Behboudi, M, Atashzadeh, F, Norian, M, Jambarsang, S \& Mohtashami, J 2014, '[The effect of aerobic exercise on fatigue stretching NICU nurses (Persian)]', Journal of Orumieh College Nursing and Midwifery, vol. 12, no. 10, pp. 1110-1118.

Benson, H, Kotch, JB \& Crass, KD 1997, 'The relaxation response: A bridge between psychiatry and medicine', Medical Clinics of North America, vol. 61, no. 4, pp. 929-39.

Chen, MC, Fang, SH \& Fang, L 2015, 'The effects of aromatherapy in relieving symptoms related to job stress among nurses', International Journal of Nursing Practice, vol. 21, no. 1, pp. 87-93.
Delpasand, M, Nasiripor, AE, Raeisi, P \& Shahabi, M 2011, '[Relationship between emotional intelligence and occupational burnout among nurses in Critical Care (Persian)]', Journal of Critical Care Nursing, vol. 4, no.2, pp. 79-86.

Gholipour Baradari, H, Mahdavi, A, Shokri Afra, G, Hosseini, HS, Yazdani Cherati, G, Emadi, ES et al 2012, '[Effect of zinc supplementation on the mental health of nurses in intensive care unit (Persian)]', Journal of Mazandaran University of Medical Sciences, vol. 22, no. 98, pp. 76-85.

Hosseini, Z, Moeini, B, Hazavei, MM, Aghamolai, T \& Moghimbigi, E 2011, 'The effect of stress management training program based on the precede model on nurses' job stress', Journal of Hormozgan University of Medical Sciences, vol. 15, no. 3, pp. 200-208.

Johansson, S, Kottorp, A, Lee ,KA, Gay, GL \& Lerdal, A 2014, 'Can the Fatigue Severity Scale 7-item version be used across different patient populations as a generic fatigue measure-a comparative study using a Rasch model approach', Health and Quality of Life Outcomes Journal, vol. 12, no. 24, pp. 1-9.

Komjathy, L 2015, Contemplative Literature: A Comparative Sourcebook on Meditation and Contemplative prayer, State University of New York Press, New York.

Kushan, M, Rakhshani, MH, Mohsenpour, M \& Heshmatifar, N 2013, '[The effect of Benson Relaxation Response on Hemodialysis Patients' Fatigue (Persian)]', Journal of Sabzevar University of Medical Sciences, vol. 20, no. 5, pp. 757-765.

Kuerer, H, Eberlein, T, Pollock, R, Huschka, M, Baile, W \& Morrow, M 2007, 'Career satisfaction,practice patterns and burn out among surgical oncologists: Report on the quality of life of members ofthe society of surgical oncology', Journal of Annals of Surgical Oncology, vol. 14, no. 11, pp.3043-3053.

Meadors, TP \& Lamson, TA 2008, 'Compassion Fatigue and Secondary Traumatization', Provider Self Care on Intensive Care Units for Children, vol. 22, no. 1, pp. 24-34.

Memarian, R 2011, Apply concepts and theories of nursing, Tarbiat Modarres University Press, Tehran.

Morse, G, Salyers, MP, Rollins, A, Monroe, M \& Pfahler, C 2012 'Burnout in Mental Health Services: A Review of the Problem and Its Remediation', Administration and Policy in Mental Health and Mental Health Services Research, vol. 39, no. 5, pp. 341-352.

Monahan, F, Sands, J, Nighbors, M, Marek, J \& Green, C 2007, Phipps' Medical-Surgical Nursing: Health and Illness Perspectives, $8^{\text {th }}$ edn, Mosby, Elsevier.

Norian, K, Parvin, N \& Mehrabi, T 2010, '[The relationship job stressors associated with public health nurses working in teaching hospitals affiliated to Isfahan University of Medical Sciences (Persian)]', Quarterly of Rafsanjan of School of Nursing and Midwifery, vol .6, no. 1-2, pp. 45-52.

Raftopoulos, V, Charalambous, A \& Talias, M 2012,'The factors associated with the burnout syndrome and fatigue in Cypriot nurses: A census report', BMC Public Health, vol. 12, no.1, pp. 457.

Salamzadeh, I, Mansori, H \& Farid, D 2008, '[The relationship between quality of work life and productivity of human resources in health care centers (Persian)]', Journal of Urmia Nursing and Midwifery Faculty, vol. 6, no. 2, pp. 60-69. 
Samadpour, T 2009, [Stress in nursing and strategies to deal with it (Persian)], Noore Danesh Press, Tehran.

Salehpour, G, Kafi, SM, Rzaei, S, Huosinnejad, M \& Salehi, I 2012, 'The Relation between Fatigue Severity with Psychological Symptoms and Quality of Life in Multiple Sclerosis', Zahedan Journal of Research in Medical Sciences, vol. 14, no. 9, pp. 80-86.

Sanjeri, M, Shirazi, F, Hidari, S, Malaki, S \& Salami, S 2009, '[The relationship between sleep and the incidence of occupational injuries among nurses (Persian)', Iran Journal of Nursing, vol. 22, no. 61, pp. 32-41.

Saremi, M \& Falah, M 2013, '[Examine the relationship between fatigue and intensity of medical errors in a teaching hospital nurse in Tehran (Persian)]', Iran Occupational Health Journal, vol. 10, no. 4, pp. 1-8.

Shahsavari, H, Moeini, M, Zare, Z \& Dosti, M 2008, [Anxiety and related nursing care (Persian)], Kankash Publications, Esfahan.

Shahriari, Z, Miri, MR, Sharifzadeh, GR, Dastjerdi, R \& Valavi M 2012, 'Effect of relaxation training on stress, anxiety and depression of mothers of mentally retarded girls, Modern Care Journal, vol. 9, no. 4, pp. 279-284.

Smeltzer, S, Bare, B, Hinkle, J \& Cheever, K 2010, 'Biophysical and pychological concepts in nursing practice', in JL Hinkle \& KH Cheever (eds.), Brunner $\mathcal{E}$ suddarths text book of medical surgical nursing, Woltres, Philadelphia.

Troy, NW \& Daglas-Pelish, P 2003, 'The effectiveness of a selfcare intervention for the management of postpartum fatigue', Applied Nursing Research, vol. 16, no. 1, pp. 38-45.

Valko, PO, Bassetti, CL, Bloch, KE, Held, U \& Baumann, CR 2008, 'Validation of the Fatigue Severity Scale in a Swiss Cohort', Journal of Sleep, vol. 31, no. 11, pp. 1601-1607.

Yaghobinia, F, Mazlom, SR, Salehi, G \& Esmaili, H 2003, '[The relationship between self-esteem and burnout in nurses working in hospitals in Mashhad University of Medical Sciences (Persian) ]', Journal of Sabzevar University of Medical Sciences, vol. 10, no. 3, pp. 73-79. 